\title{
Mortality of First Permanent Molars among 6-12 Years Old Children Attending Dental Hospital / College of Dentistry, University of Baghdad
}

\author{
Rusul J. Haddi ${ }^{1}$, Nada Jafer MH. Radhi ${ }^{2}$ \\ ${ }^{1}$ B.D.S., Pedodontic and Preventive dentistry department, Baghdad University, College of Dentistry
}

${ }^{2}$ B.D.S., M.Sc., Ph.D., Assist. Prof., Baghdad University, College of Dentistry, Head of Pedodontic and Preventive Dentistry Department

\begin{abstract}
Background: The first permanent molars are the leading teeth among the series of permanent dentition, with no primary predecessor. The aim of the present study was to estimate the mortality of first permanent molars and severity of dental caries. Materials and methods: The sample composed of (84) children (39 males and 45 females) attending dental hospital /College of Dentistry, University of Baghdad. The age ranged from 6-12 years. Decayed, missing and filled surfaces index (DMFS) was used for recording caries-experience according to WHO (1987). Statistical analysis was done by using statistical package for social sciences (SPSS) version 18. Results: The rate of caries free was the highest in males at the age 6 years, which reached (83.3\%). A higher percentage of missing first permanent molar was noticed at age of 7 years (5.5\%). The mean value of DMFS was higher among females (4.57 \pm 2.57$)$ than males (3.58 +2.69$)$.The percentage of children with missing one first permanent molar in the lower jaw was (3.8\%). While a higher percentage (59.7\%) were found with two decayed teeth in the lower jaw. Conclusion: The present study reported a higher percentage of children with decayed and missing first permanent molars in the lower jaw compared to the upper jaw. A preventive program should be developed early in life and more care should be given to conserve the first permanent molars.
\end{abstract}

Keywords: Mortality, First permanent Molars, caries, DMFS

\section{Introduction}

The morphology, time of eruption and positioning of the tooth in the oral cavity confers an inherent disadvantage/advantage to the various methods employed in the control of plaque and hence tooth decay/losses [1]. It was reported that tooth loss due to extraction is mainly due to extensive caries with loss of the maximum amount of tooth structure and its sequelae including failed conservative procedures and also advance periodontal disease, extraction to some extent reflect the pattern and prevalence of major dental disease in a population [2]. The first permanent molar is unquestionably the most important unit of mastication and is essential in the development of functionally desirable occlusion. The first permanent molars were more susceptible to dental caries and they have the highest caries attack rate among the permanent dentition. The molar teeth have many grooves (fissures) and pits on the chewing (occlusal) surfaces and on the buccal and palatal surfaces, which can be very difficult to keep clean. These sites are most susceptible to developing decay ${ }^{[3]}$. At about the age of 6 , the first permanent molar will erupt behind the four ends of deciduous teeth; it is also called the six-year molar [4]. Due to the importance of these teeth in the dentition, as their surfaces would need to be sealed, this is considered as the most cost-effective way [5]. Previous studies in Iraq and the world were reported different findings regarding caries experience and mortality of first permanent molars among children and adolescents $[6,7,8,9,10]$. The present study is aimed at identifying the mortality and caries experience of first permanent molars among children attending dental hospital in College of Dentistry/University of Baghdad. The result will facilitate the development of an approach in treatments relevant to the problem and assist in addressing the oral health needs of the society, thus minimizing tooth loss.

\section{Materials and Methods}

The sample: The total sample composed of (84) children (39 males and 45 females) with an age of 6-12 years. Those children were attending the Prevention and Pedodontics dental clinic in the College of Dentistry, University of Baghdad as a first visit. Out of total number of children were two females (aged 6 and 7 years old) excluded because they did not have erupted permanent molars. The patient who have been examined at first visit, would not be examined again if came for another visit.All selected children were examined for dentalcaries by disposable mirror and explorer utilizing the World Health Organization WHO 1987criteria [11] for thediagnosis of dental caries.

Pilot study: Intra and inter calibration regarding dental caries were done to obtain the most critical consistency of data.

Statistical analysis: Data were translated into a computerized database structure. Statistical analysis was done by using SPSS version 18. This includes frequency distribution, Mean and standard deviation were described the caries status assessment.

\section{Results}

Caries free children were demonstrated according to age and gender as showed in Table (3-1). Results showed that children at age 6 years were more caries free than the other age groups. For all age groups, total males demonstrated a higher percentage of caries free than total females.

Volume 6 Issue 12, December 2017 


\section{International Journal of Science and Research (IJSR)}

ISSN (Online): 2319-7064

Index Copernicus Value (2016): 79.57 | Impact Factor (2015): 6.391

Table (3-1): Distribution of Total Sample, Caries Free Children by Age and Gender.

\begin{tabular}{|c|c|c|c|c|}
\hline \multirow[t]{2}{*}{ Age } & \multirow[t]{2}{*}{ Gender } & \multirow{2}{*}{$\begin{array}{l}\text { Total No. } \\
(\%)\end{array}$} & \multicolumn{2}{|c|}{ Caries Free } \\
\hline & & & No. & $\%$ \\
\hline \multirow[t]{3}{*}{6} & $\mathrm{M}$ & $6(7.1)$ & 5 & 83.3 \\
\hline & $\mathrm{F}$ & $2(2.4)$ & 0 & 0 \\
\hline & $\mathrm{T}$ & $8(9.5)$ & 5 & 62.5 \\
\hline \multirow{3}{*}{7} & $\mathrm{M}$ & $5(6.0)$ & 0 & 0 \\
\hline & $\mathrm{F}$ & $4(4.8)$ & 1 & 25 \\
\hline & $\mathrm{T}$ & 9(10.8) & 1 & 11.1 \\
\hline \multirow{3}{*}{8} & M & $5(6.0)$ & 1 & 20 \\
\hline & $\mathrm{F}$ & $12(14.3)$ & 0 & 0 \\
\hline & $\mathrm{T}$ & $17(20.3)$ & 1 & 5.8 \\
\hline \multirow{3}{*}{9} & M & $4(4.7)$ & 0 & 0 \\
\hline & $\mathrm{F}$ & $7(8.3)$ & 0 & 0 \\
\hline & $\mathrm{T}$ & $11(13.0)$ & 0 & 0 \\
\hline \multirow{3}{*}{10} & M & $4(4.8)$ & 0 & 0 \\
\hline & $\mathrm{F}$ & $5(5.9)$ & 0 & 0 \\
\hline & $\mathrm{T}$ & $9(10.7)$ & 0 & 0 \\
\hline \multirow{3}{*}{11} & $\mathrm{M}$ & $3(3.5)$ & 0 & 0 \\
\hline & $\mathrm{F}$ & $8(9.5)$ & 0 & 0 \\
\hline & $\mathrm{T}$ & 11(13.0) & 0 & 0 \\
\hline \multirow[t]{3}{*}{12} & $\mathrm{M}$ & $12(14.3)$ & 0 & 0 \\
\hline & $\mathrm{F}$ & $7(8.4)$ & 0 & 0 \\
\hline & $\mathrm{T}$ & 19(2.7) & 0 & 0 \\
\hline \multirow{3}{*}{ All } & M & $39(46.4)$ & 6 & 15.3 \\
\hline & $\mathrm{F}$ & $45(53.6)$ & 1 & 2.2 \\
\hline & $\mathrm{T}$ & $84(100.0)$ & 7 & 8.3 \\
\hline
\end{tabular}

Table (3-2) illustrates the distribution of missing first permanent molars due to caries by age. Results reveled that the children at age 7 years were had the higher percentage $(5.5 \%)$ than the other age groups, while the children at age $(6,11)$ years were had no missing first permanent molars.

Table (3-2):Distribution of Missing First Permanent Molars due to Caries by Age

\begin{tabular}{|c|c|c|c|c|}
\hline \multirow[b]{2}{*}{ Age } & \multirow[b]{2}{*}{ No. } & \multirow[b]{2}{*}{ No. of teeth } & \multicolumn{2}{|c|}{ Missing teeth } \\
\hline & & & No. & $\%$ \\
\hline 6 & 8 & 28 & 0 & 0 \\
\hline 7 & 9 & 36 & 2 & 5.5 \\
\hline 8 & 17 & 68 & 3 & 4.4 \\
\hline 9 & 11 & 44 & 1 & 2.2 \\
\hline 10 & 9 & 36 & 1 & 2.7 \\
\hline 11 & 11 & 44 & 0 & 0 \\
\hline 12 & 19 & 76 & 1 & 1.3 \\
\hline Total & 84 & 332 & 8 & 2.4 \\
\hline
\end{tabular}

Table (3-3) illustrates the caries-experience (DMFS) of first permanent molars among children according to gender. Results revealed that Decayed fraction (DS) of DMFS contributing the major part than the other fractions. The mean values of decayed surfaces (DS) and missing surfaces (MS) were found higher among females compared to males, while the mean value of filled surfaces (FS) was higher in males compared to females. Females demonstrated higher mean value of DMFS compared to males.
Table (3-3): Caries-Experience (DMFS: Mean and Standard Deviation) of First Permanent Molars among Children

\begin{tabular}{|c|c|c|c|c|c|}
\multicolumn{7}{|c}{ according to Gender. } \\
\hline Gender & No. & $\begin{array}{c}D S \\
\text { Mean } \pm S D\end{array}$ & $\begin{array}{c}M S \\
\text { Mean } \pm S D\end{array}$ & $\begin{array}{c}F S \\
\text { Mean } \pm S D\end{array}$ & $\begin{array}{c}\text { DMFS } \\
\text { Mean } \pm S D\end{array}$ \\
\hline$M$ & 39 & $2.84 \pm 2.17$ & $0.26 \pm 1.11$ & $0.48 \pm 1.07$ & $3.58 \pm 2.69$ \\
\hline$F$ & 45 & $3.55 \pm 1.81$ & $0.66 \pm 2.28$ & $0.36 \pm 0.82$ & $4.57 \pm 2.57$ \\
\hline$T$ & 84 & $3.22 \pm 2.00$ & $0.48 \pm 1.83$ & $0.41 \pm 0.94$ & $4.11 \pm 2.65$ \\
\hline
\end{tabular}

Table (3-4) represents the distribution of children according to caries status; Decayed teeth (DT), Missing teeth (MT) by location. Results showed that a higher percentage of children were had decayed teeth in one and both sides of the lower jaw compared to the upper jaw. Concerning missing teeth, a higher percentage of children had a missing tooth in one side of the lower jaw. While an equal percentage of children were found with the missing teeth in both sides of upper jaw. Results revealed the sextant distribution of first permanent molars extraction (eight teeth) due to caries (upper right $=12.5 \%$; upper left=25\%; lower left=37.5\%; lower right $=25 \%$ ).

Table (3-4): Distribution of Children according to Caries Status; Decayed teeth (DT), Missing teeth (MT) by Location.

\begin{tabular}{|c|c|c|c|c|c|c|c|c|}
\hline \multirow{2}{*}{ Location } & \multicolumn{8}{|c|}{ Total No. of Children $=77$} \\
\cline { 2 - 9 } & \multicolumn{2}{|c|}{$1 D T$} & \multicolumn{2}{|c|}{$2 D T$} & \multicolumn{2}{|c|}{$1 M T$} & \multicolumn{2}{|c|}{$2 M T$} \\
\cline { 2 - 9 } & No. & $\%$ & No. & $\%$ & No. & $\%$ & No. & $\%$ \\
\hline Upper Jaw & 15 & 19.4 & 41 & 53.2 & 1 & 1.2 & 1 & 1.2 \\
\hline Lower Jaw & 23 & 29.8 & 46 & 59.7 & 3 & 3.8 & 1 & 1.2 \\
\hline
\end{tabular}

\section{Discussion}

The first permanent molar is the first permanent tooth erupts in the oral cavity, as a consequence of the significance of their positions and the circumstances surrounding their eruption. This study was found that at age of six years, a higher percentage rate of caries free children were noticed than the other age groups, other studies also reported the same findings $[6,9,10]$. This may be due to the irreversibility and accumulative nature of dental caries as dental caries need enough time to develop and first permanent molar is begins to erupt at age six years [12] Thus, age is an important variable that should always be taken in account in caries studies. The study also showed the distribution of missing first permanent molar due to caries was in higher percentage at age 7 years than other age groups, while other study found that age 12 had the higher percentage [6]. This may explain the negligence of dental health among these children due to limitation in the knowledge of keeping first permanent molars.

The DMFS index is used because it is more sensitive index for caries intensity since caries is measured by surface rather than teeth. The present study revealed that higher mean values of DMFS of first permanent molars were found among females than males. While other study found the opposite results [9]. This can be explained that the first permanent molars erupt earlier in females than males $[13,14$, $15,16]$, thus exposed more to environmental factors [17].The first permanent molars are considered the "cornerstones" of the dental arches [18]. This tooth is more vulnerable to caries than others because of its functional and 


\section{International Journal of Science and Research (IJSR) \\ ISSN (Online): 2319-7064}

Index Copernicus Value (2016): 79.57 | Impact Factor (2015): 6.391

morphological characteristics; an increase in carious lesion development would manifest itself first in pits and fissures [5].

The present study recorded that the higher percentage of children were found with decayed and missing teeth in lower jaw than the upper jaw, this finding concurrent with other studies $[19,10]$. This may be due to morphology and eruption time of the tooth. Mandibular first permanent molar has more number of pits and supplementary grooves which can act as food retentive areas promoting caries. The other factor could be that in majority of children mandibular first permanent molar erupts slightly earlier than its maxillary counterpart, hence mandibular first permanent molar being exposed to the oral environment for a longer period of time, making it more susceptible to caries than maxillary first permanent molar [10]. The results of present study revealed a higher caries-experience of first permanent molars among children. Thus, it is recommended that an oral care preventive program should be considered for those children.

\section{Conclusion}

The present study reported the caries status of first permanent molars among males and females were attending Dental Hospital/ College of Dentistry, University of Baghdad. It was noticed a higher percentage of children with decayed and missing first permanent molars in the lower jaw compared to the upper jaw. A preventive program should be developed early in life and more care should be given to conserve the first permanent molars and prevent caries development by fissure sealant or by prompt treatment of early lesion.

\section{References}

[1] Damle S. Textbook of Pediatric Dentistry. 3rd ed. Arya (Medi) Publishing House, New Delhi, 2009.

[2] Upadhyaya C, Humagain M. The pattern of tooth loss due to dental caries and periodontal disease patients attending dental department (OPD), Dhulikhel hospital, Kathmandu university teaching hospital (KUTH), Nepal. Kathmandu University Medical Journal 2009; 7(1):59-62.

[3] Ahovuo-Saloranta A, Hiiri A, Nordblad A. Pit and fissure sealants for preventing dental decay in the permanent teeth of children and adolescents. Cochrane Database Syst Rev 2008; 4:CD001830.

[4] Clements EMB, Davies-Thomas E, Pickett KG. Time of eruption of permanent teeth in British children at independent, rural, and urban schools. Br Med J 2009; $1: 1-3$.

[5] Yengopal V, Mickenautsch S, Bezerra AC. Cariespreventive effect of glass ionomer and resin-based fissure sealants on permanent teeth: a Meta analysis. J Oral Sci 2009; 51(6):373-382.

[6] Al Sayyab M, Al Alousi W, El-Samarrai S. Mortality of first permanent molars among Iraqi children living in two Iraqi villages (Sheha, AlbuEtha). J CollDentsitry 1998; 2:261-265.

[7] Skeie M. Dental caries in children aged 3-10 years, Norway. Main Thesis, University of Bergen, 2005.
[8] Hopcraft MS, Morgan MV: Comparison of radiographic and clinical diagnosis of approximal and occlusal dental caries in a young adult population. Community Dent Oral Epidemiol 2006: 33:212-218.

[9] Mohammed A. Caries experience of the first permanent molars among agroup of children attending pedodontics' Clinic College of Dentistry. J Bagh College Dentistry 2011; 23(3):117-119.

[10] Togoo R, Yaseen S, Zakirulla M, Al Garni F, Khorage A, Meer A. Prevalence of first permanent molar caries among 7-10 years old school Going boys in Abha city, Saudi Arabia. J International Oral Health 2011; 3:29-34.

[11]WHO, Oral health surveys- basic methods, 3rd ed. World Health Organization. Geneva, Switzerland, 1987.

[12] Thylstrup A. and Fejerskov O. Textbook of clinical cariology, 2nd ed. Munksgaard, Copenhagen, 1996.

[13] Al Sayyab M, Al Alousi W, El-Samarrai S. Mortality of first permanent molars among Iraqi children living in two Iraqi villages (Sheha, AlbuEtha). J CollDentsitry 1998; 2:261-265.

[14] Al-Farhan S. Aspects of dental health in Iraq. M.Sc. Thesis, University of Dundee, 1976.

[15] Ghose LJ and Baghdady VS. Eruption time of permanent teeth in Iraqi school children. Arch Oral Biol 1981; 26 (1): 13-15.

[16] Teivens A, Mörnstad H, Reventlid M. Individual variation of tooth development in Swedish Children. Swed Dent J 1996; 20(3):87-93.

[17] Ghalib NB. Eruption time of permanent teeth in Iraqi school children. Iraqi Dent J 1998. (Accepted for publication).

[18] McDonald RE, Avery DR, Dean J. Dentistry for the child and adolescent. $8^{\text {th }}$ ed. Philadelphia, USA, 2004.

[19] Ekstrand KR, Christiansen J, Christiansen ME. Time and duration of eruption of first and second permanent molars: a longitudinal investigation. Community Dent Oral Epidemiol 2003; 31: 344-50.

[20] Serban V, Balan A. Study on the Caries of the first permanent molar in children aged between 6 and 13 years. J Roman Med Dent 2009; 13(4):138-41. 